\title{
Nanostructured polymer scaffolds for tissue engineering and regenerative medicine
}

\author{
I. O. Smith, ${ }^{1}$ X. H. Liu, ${ }^{1}$ L. A. Smith ${ }^{1,2}$ and P. X. Ma1,2,3*
}

The structural features of tissue engineering scaffolds affect cell response and must be engineered to support cell adhesion, proliferation and differentiation. The scaffold acts as an interim synthetic extracellular matrix (ECM) that cells interact with prior to forming a new tissue. In this review, bone tissue engineering is used as the primary example for the sake of brevity. We focus on nanofibrous scaffolds and the incorporation of other components including other nanofeatures into the scaffold structure. Since the ECM is comprised in large part of collagen fibers, between 50 and $500 \mathrm{~nm}$ in diameter, well-designed nanofibrous scaffolds mimic this structure. Our group has developed a novel thermally induced phase separation (TIPS) process in which a solution of biodegradable polymer is cast into a porous scaffold, resulting in a nanofibrous pore-wall structure. These nanoscale fibers have a diameter $(50-500 \mathrm{~nm})$ comparable to those collagen fibers found in the ECM. This process can then be combined with a porogen leaching technique, also developed by our group, to engineer an interconnected pore structure that promotes cell migration and tissue ingrowth in three dimensions. To improve upon efforts to incorporate a ceramic component into polymer scaffolds by mixing, our group has also developed a technique where apatite crystals are grown onto biodegradable polymer scaffolds by soaking them in simulated body fluid (SBF). By changing the polymer used, the concentration of ions in the SBF and by varying the treatment time, the size and distribution of these crystals are varied. Work is currently being done to improve the distribution of these crystals throughout three-dimensional scaffolds and to create nanoscale apatite deposits that better mimic those found in the ECM. In both nanofibrous and composite scaffolds, cell adhesion, proliferation and differentiation improved when compared to control scaffolds. Additionally, composite scaffolds showed a decrease in incidence of apoptosis when compared to polymer control in bone tissue engineering. Nanoparticles have been integrated into the nanostructured scaffolds to deliver biologically active molecules such as growth and differentiation factors to regulate cell behavior for optimal tissue regeneration. @ 2009 John Wiley \& Sons, Inc. WIREs Nanomed Nanobiotechnol 20091 226-236

$\mathrm{T}_{\mathrm{i}}^{\mathrm{h}}$ The need for readily available replacement tissue is greater than ever. As of 2004, over $1.5 \mathrm{~m}$ tissue graft procedures are performed each year

\footnotetext{
*Correspondence to: mapx@umich.edu

${ }^{1}$ Department of Biologic and Materials Science, The University of Michigan, Ann Arbor, MI, USA

${ }^{2}$ Department of Biomedical Engineering, The University of Michigan, Ann Arbor, MI, USA

${ }^{3}$ Macromolecular Science and Engineering Center, The University of Michigan, Ann Arbor, MI, USA

DOI: $10.1002 /$ wnan.026
}

in the USA alone, ${ }^{1}$ of which it is estimated that 500,000 are bone tissue grafts. ${ }^{2}$ The current gold standard for bone tissue grafts is the autograft, which involves some inherent issues. The retrieval of autograft tissue requires surgery at a second site, presenting the possibility of complications, including infection and donor site morbidity. Allograft tissue is another option, but has its own inherent risk for complications, including its limited supply, as well as the possibility of disease transmission and tissue rejection. The growth of replacement tissue using tissue engineering and regenerative medicine is one 
method of using technology to create an effective replacement for these types of graft tissue.

Tissue engineering is a field in which our knowledge in the life sciences and medical fields is applied using engineering principles, in order to design therapeutic treatments that positively affect tissue function. ${ }^{3}$ While tissue engineering encompasses three approaches, cells and cell substitutes, factors for tissue induction, and the seeding of cells onto matrices, the most common tissue engineering approach is the third one, to place cells onto a biomaterial matrix. ${ }^{3}$ This combination is designed to grow tissue in vitro, prior to implantation within the subject.

The design of the scaffold prior to exposure to cells is of vital importance. The scaffold must present a surface that promotes cell attachment, growth and differentiation, while providing a porous network for tissue growth. ${ }^{4,5}$ The material chosen is of great importance when designing a scaffold. It must degrade at a rate matching that of the new tissue formation, must be biocompatible and the products of its degradation must also be biocompatible. Once implanted, the scaffold must have the mechanical properties necessary to temporarily offer structural support until the new tissue has formed. In addition to consisting of an effective biomaterial, the scaffold must also possess key morphological characteristics. It must be highly porous and offer a suitable path for nutrient transmission and tissue ingrowth. To achieve these requirements, tissue engineering scaffolds are often designed to mimic the structure of the naturally occurring extracellular matrix (ECM). ${ }^{6,7}$

During bone tissue formation, collagen fibers between 50 and $500 \mathrm{~nm}$ in diameter are deposited as part of the ECM. ${ }^{8}$ These fibers act as a construct, onto which apatite crystals are deposited, forming the earliest phase of bone. This fibrous collagen may play an important role in regulating cell attachment, proliferation and differentiation and trends in scaffold design have aimed to better mimic this structure. ${ }^{6,7}$

This review is focused on the forefront of nanoscale aspects of scaffold design, including the design of novel techniques for fabricating nanofibrous polymer scaffolds, nanoscale polymer/ceramic composite scaffolds and nanoparticle integrated factor delivery scaffolds, as well as how these features affect cell response. While these techniques are applicable to many types of tissue, this review focuses on bone tissue engineering.

\section{NANOSTRUCTURED POLYMER SCAFFOLD FABRICATION}

\section{Methods of Nanofiber Fabrication}

Three different methods have been employed in the fabrication of nanofibrous scaffolds for tissue engineering: electrospinning, self-assembly, and phase separation. The electrospinning process was first patented in the 1900s. ${ }^{9}$ The principle of electrospinning is to use an electric field to draw a polymer solution from an orifice to a collector, producing polymer fibers with diameters in the range of nanometers to micrometers. ${ }^{9,10}$ As a result of the simplicity of this method, electrospinning has received considerable attention for use in tissue engineering. A variety of synthetic and natural biomaterials, including poly(lactic-co-glycolic acid) (PLGA), poly(L-lactic acid) (PLLA), poly(caprolactone) (PCL), poly(ethylene oxide) (PEO), poly(vinyl alcohol) (PVA), gelatin, collagen, silk protein and fibrinogen have been used to form nanofibrous scaffolds for tissue engineering. ${ }^{11-21}$ In general, the diameters of electrospun fibers are at least one or two orders of magnitude smaller than those of fibers fabricated by conventional extrusion methods. However, electrospinning typically is used to produce thin two-dimensional (2D) sheets. While three-dimensional (3D) nanofibrous scaffolds have been fabricated by layering these $2 \mathrm{D}$ sheets, ${ }^{22}$ it is inherently difficult to create 3D scaffolds with a welldefined pore architecture and complex geometries, including interconnected macropore networks. Initial attempts at combining electrospinning with 3D printing have yielded some success, ${ }^{23}$ but further assessment of this process is needed.

Molecular self-assembly is a useful approach for fabricating supramolecular architectures. ${ }^{24}$ Molecular self-assembly is mediated by noncovalent bonds such as hydrogen bonds and van der Waals, electrostatic, and hydrophobic interactions. Selfassembled molecules are ubiquitous in nature. Biomolecules, such as peptides and proteins, interact and self-organize to form well-defined architectures that are associated with functionality. Under certain conditions, nanostructured fibers can be formed by molecular self-assembly. ${ }^{25,26}$ The fiber diameter created by molecular self-assembly usually is much smaller than those produced using electrospinning. ${ }^{27}$ While molecular self-assembly is a fairly new technique for the formation of nanoscale scaffolds, it has limited ability to form macropores, which are important for cell accommodation and mass transport. The mechanical properties of self-assembled scaffolds also have to be improved before they can be used in many tissue engineering applications. 

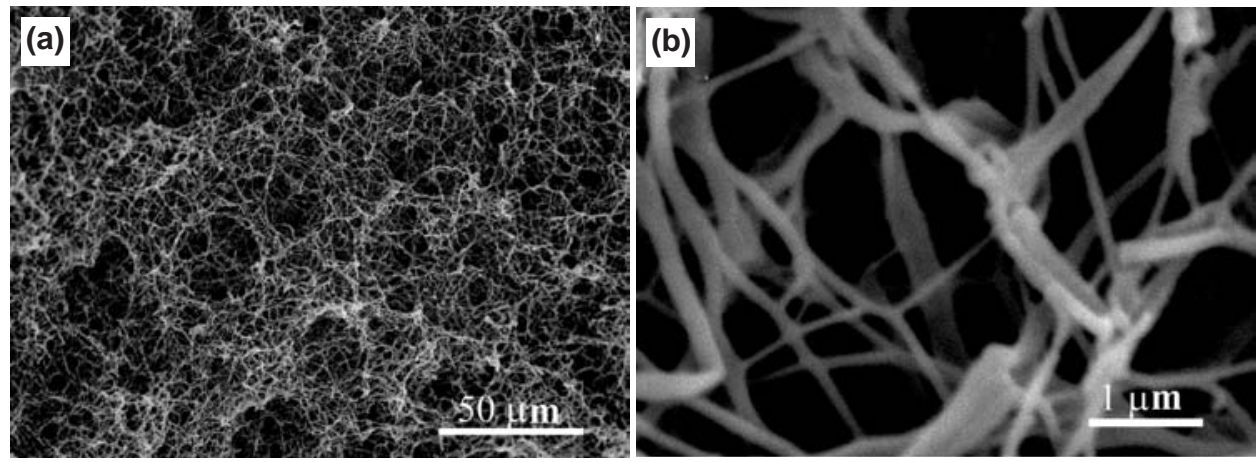

FIGURE 1 | Scanning electron microscope micrographs of a poly(I-lactic acid) (PLLA) fibrous matrix prepared from $2.5 \%(\mathrm{wt} / \mathrm{v}$ ) PLLA/tetrahydrofuran solution at a gelation temperature of $8^{\circ} \mathrm{C}$ : (a) $\times 50$; (b) $\times 20$ K. (Reprinted, with permission, from Ref. 6 . Copyright 1999 Wiley Periodicals, Inc.).

A novel thermally induced phase separation (TIPS) technique was developed recently to fabricate nanofibers to mimic natural collagen fibers. ${ }^{6}$ The TIPS process for nanofiber formation typically includes five steps: polymer dissolution, phase separation and gelation, solvent extraction, freezing, and freezedrying under vacuum. The fiber network formation depends on the solvent of the polymer solution and the gelation temperature. The fibers formed in this manner have diameters ranging from 50 to $500 \mathrm{~nm}$, and have a porosity in excess of $98 \%$ (Figure 1). This nanofibrous matrix has a much higher surface-to-volume ratio than those of fibrous nonwoven fabrics fabricated with the textile technology or foam fabricated with other techniques. ${ }^{6,28}$ A distinct advantage of the TIPS technique is that it can be combined with other processing techniques (such as particulate leaching or $3 \mathrm{D}$ printing) to design complex $3 \mathrm{D}$ structures with well-defined pore morphologies. ${ }^{28-30}$ In the next section, we present a few examples to illustrate how the TIPS technique is combined with other technologies to create 3D nanofibrous scaffolds with predesigned macropores.

\section{Three-Dimensional Nanofibrous Scaffolds with Predesigned Macropores}

To engineer functional tissues and organs successfully, the scaffolds have to be designed to facilitate cell distribution and guide tissue regeneration in three dimensions. Macroscopic pores $(>100 \mu \mathrm{m})$ in a scaffold play an important role in cell seeding distribution, cell migration throughout the 3D space, and neo-vascularization after implantation of the scaffold in vivo. ${ }^{5}$

To create a nanofibrous matrix with a macroscopic pore network, a combination of TIPS and particulate leaching can be used. ${ }^{7}$ In one example, PLLA-THF (tetrahydrofuran) polymer solution was dripped slowly onto sugar particles in a mold and then cooled to a preset gelation temperature. After phase separation, the gel-sugar composite was immersed in distilled water to simultaneously extract the solvent and leach the sugar from the composite. The sample was freeze-dried, resulting in a 3D nanofibrous matrix with macropores left from the leached sugar particles. ${ }^{7}$

In addition to pore size, pore interconnectivity in a scaffold is also important for cell migration, cell signaling, and mass transport. While particle leaching techniques can create well formed macropores, it is difficult to control the degree of interconnectivity. To better control the interconnectivity of the macropores in a scaffold, our group developed several novel molding techniques. ${ }^{4,28,31}$ By combining these techniques with TIPS technique, 3D nanofibrous scaffolds with well-controlled interconnectivity are created (Figure 2).
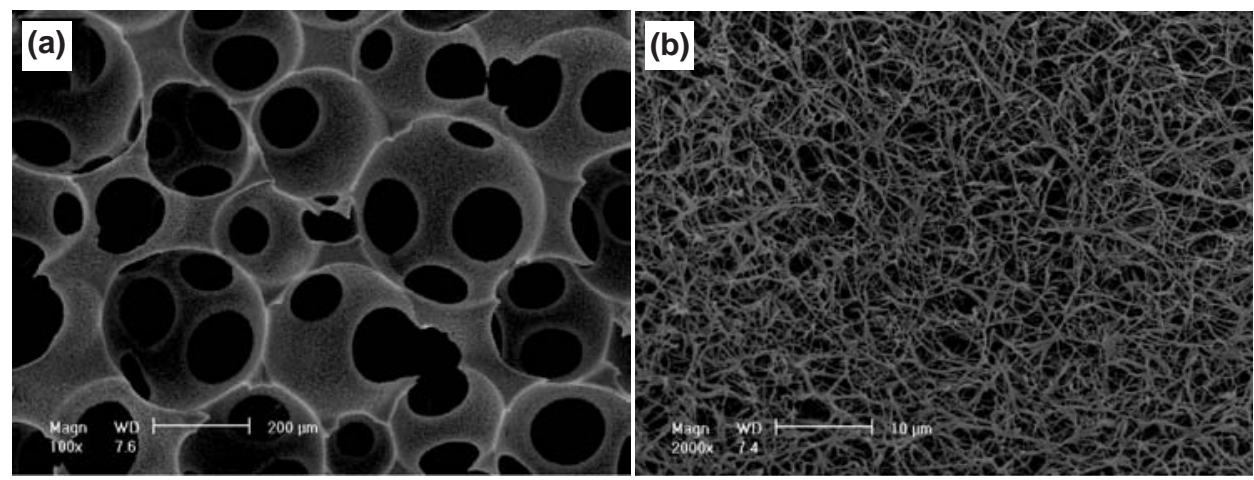

FIGURE 2 | SEM images of nanofibrous PLLA (NF-PLLA) scaffolds. (a) $\times 100$, (b) $\times 2000$. (Reprinted, with permission, from Ref. 32. Copyright 2005 American Scientific Publishers.). 
FIGURE 3 | SEM micrographs of poly(I-lactic acid) (PLLA) nanofibrous scaffolds with incorporated PLGA50-64K nanospheres. (Reprinted, with permission, from Ref. 41. Copyright 2007 Elsevier).
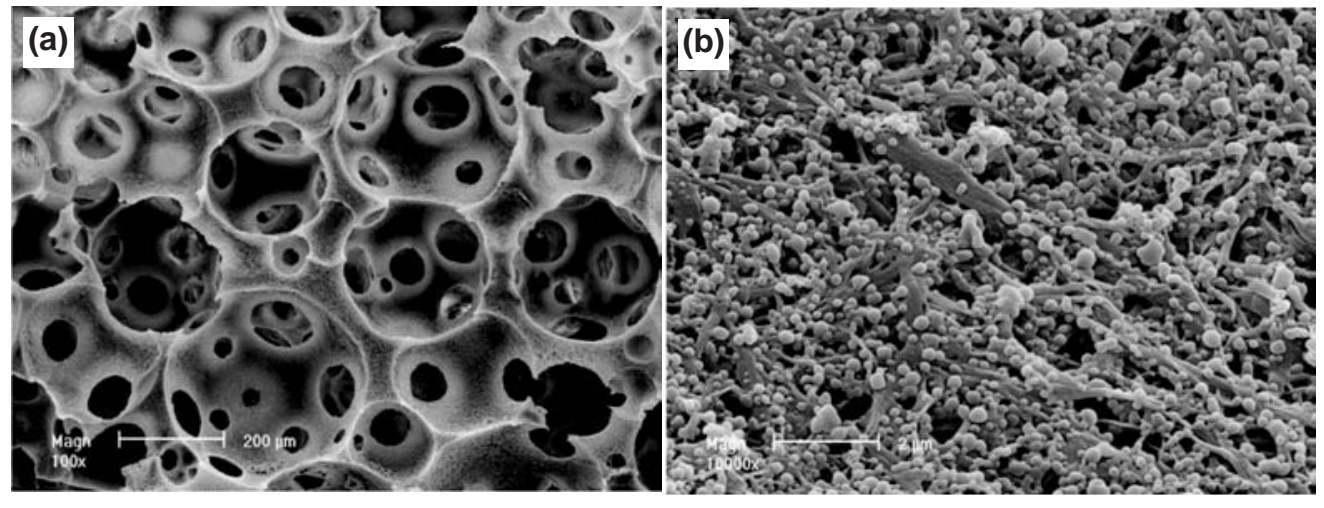

\section{Surface Modification of Nanofibrous Scaffolds}

In tissue engineering, it is important to consider the interactions of cells with the scaffold materials. The nature of the scaffold surface can directly affect cellular response, ultimately influencing the rate and quality of new tissue formation. ${ }^{33,34}$ Although a variety of synthetic biodegradable polymers have been used as tissue engineering scaffold materials, one disadvantage of these scaffolds is a lack of biological recognition on their surface. Therefore, the scaffold surface has to be modified to obtain more desirable characteristics to promote cell-scaffold interactions. ${ }^{5}$

Several approaches have been developed to modify the scaffold surface. ${ }^{35-38}$ However, most of this work has been focusing on $2 \mathrm{D}$ film surfaces or very thin $3 \mathrm{D}$ constructs. True $3 \mathrm{D}$ scaffolding surface modification is still a challenge. In our lab, several effective techniques have been developed for 3D surface modification of complex shaped scaffolds. ${ }^{32,39,40}$ For example, an electrostatic layerby-layer self-assembly technique has been used to modify nanofibrous PLLA (NF-PLLA) scaffolds with gelatin. ${ }^{32}$ One advantage of this technique is that the layer-by-layer self-assembly method can be used for any complex 3D geometry as long as the pores are interconnected. Cell proliferation was more effectively facilitated on the surface-modified NF-PLLA scaffolds than on the control scaffolds. Histological slides showed that cells were distributed evenly throughout the scaffolds, and cell density on the surface-modified NF-PLLA scaffold was higher than that on the NFPLLA control scaffold.

\section{Nanospheres}

Nanoparticles are defined as being on the scale of less than $100 \mathrm{~nm}$ in diameter. They possess a high surfaceto-volume ratio, which makes them an effective vehicle for the release of biological factors such as growth factors, drugs and genes. By incorporating PLGA nanospheres, a type of nanoparticle, into nanofibrous PLLA scaffolds, recombinant human bone morphogenetic protein (rhBMP-7) was delivered to the region of cell culture, and ectopic bone formation was positively affected. ${ }^{41}$ An example of this configuration is shown in Figure 3.

\section{POLYMER/CERAMIC NANOCOMPOSITE SCAFFOLDS}

Ceramic materials have long been studied as potential candidates for bone tissue engineering applications. ${ }^{42}$ In particular, calcium phosphate $(\mathrm{CaP})$ ceramics, including hydroxyapatite (HA), have drawn interest because of their similarity to bone mineral, as well as their inherent biocompatibility and osteoconductivity. ${ }^{43,44}$ HA exhibits a strong propensity for attracting osteoblasts but possesses a low resorption rate in vivo and is brittle, especially in highly porous forms.

In order to alleviate some of these inherent issues, while still maintaining its benefits, HA has been combined with several natural and synthetic polymers, including poly(lactic acid) (PLA), ${ }^{45-50}$ PLGA, ${ }^{51,52}$ polyamide, ${ }^{53}$ PCL, ${ }^{54}$ polyethylene, ${ }^{55}$ gelatin, ${ }^{56}$ chitosan $^{57}$ and collagen ${ }^{49,58,59}$ to produce composite scaffolds. Advantages of pairing HA with natural and/or synthetic polymers include improved control of design parameters such as porosity, degradability and mechanical properties when compared to pure HA scaffolds. Porosities greater than $90 \%$ are possible, whereas pure HA scaffold porosity is usually less than $70 \% .{ }^{60}$

The addition of nanocrystalline HA to natural polymer scaffolds has been shown to improve mechanical properties compared to polymer control scaffolds ${ }^{50}$ and the presence of HA may potentially reduce adverse effects associated with the degradation of some synthetic polymers. ${ }^{61}$ 
The most common methods for fabricating polymer/HA composite scaffolds fall into two categories: incorporation during processing and biomimetically growing the apatite onto a prefabricated polymer scaffold.

\section{Incorporation of Nanoscale Ceramic into Polymer Matrix}

One method of fabricating composite scaffolds is by incorporating a ceramic component directly into the polymer solution prior to solidification. One technique used to combine HA with PLLA is TIPS. Our group has used this technique to incorporate nanocrystalline HA into PLLA, yielding composite scaffolds with porosities as high as $95 \% .{ }^{50}$ An example of this type of scaffold is shown in Figure 4. Porosity and pore morphology were controlled in two ways: by using different solvents, including pure dioxane, pure benzene and various mixtures of dioxane/water and by varying the size of the HA particles used. Using nanoscale HA powder in place of micron-scale powder resulted in a more regular network of pores. ${ }^{50}$

While these techniques have proved to be effective for low volume fractions of HA in PLLA, the incorporation of larger amounts of ceramic was prohibitive $^{50}$ and a percentage of the incorporated ceramic remained locked inside the scaffold structure.

\section{Biomimetic Polymer/Apatite Composite Scaffolds}

The methods described above create composite scaffold structures with high porosity, good interconnectivity and varying degrees of control over pore size and shape. However, these methods all involve a ceramic content that is largely contained within the bulk of the scaffold material, rather than at the surface. Since all interactions with biological components occur at the pore surface, the nonexposed ceramic is in effect wasted. In order to better utilize the ceramic component, polymer/ceramic composite scaffolds have also been fabricated using a biomimetic approach, where a prefabricated polymer scaffold is soaked in simulated body fluid (SBF) in order to allow apatite crystals to grow onto its pore surfaces. Figure 5 is an SEM micrograph showing apatite crystals on the surface of a poly-DL-lactic acid (PDLLA) scaffold. The mechanism of this process is described in detail elsewhere. ${ }^{62,63}$ This technique is simple, requires no special equipment and can be used to grow apatite onto complex scaffold structures, unlike many surface modification techniques, which require a flat surface.

The methods used to fabricate polymer scaffolds to be soaked in SBF vary. Thin scaffolds on which apatite has been successfully grown have been created using electrospinning techniques. ${ }^{35}$ However, this method normally yields a roughly two-dimensional
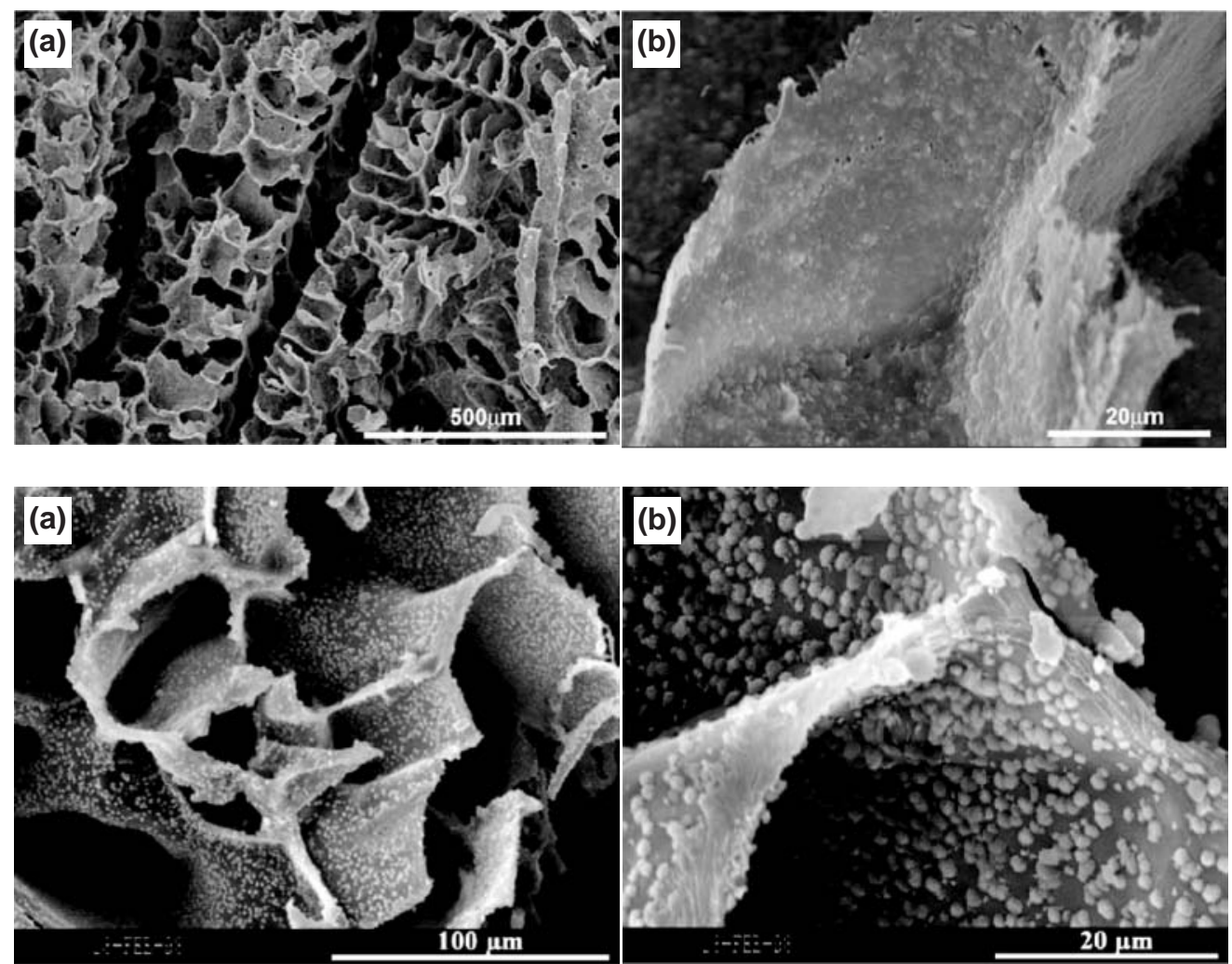

FIG URE 4 | SEM

micrographs of nanoHA/PLLA 50 : 50 scaffold, $\times 100, \times 1000$. (Reprinted, with permission, from Ref. 50. Copyright 2004 Elsevier).

FIGURE 5 | SEM micrographs of PDLLA scaffolds incubated in $1.5 \times$ SBF for 30 days. (Reprinted, with permission, from Ref. 52. Copyright 2004 Wiley Periodicals, Inc.). 
product that is not practical for use in large bone defects. TIPS has been used repeatedly and with much success. ${ }^{46,52}$ By varying the solvents used and the polymer concentration, porosity and pore morphology are optimized to allow apatite deposition throughout the three-dimensional scaffold construct. Porogens have also been used to control pore shape, size and interconnectivity, including the inclusion and leaching of salt particles and sugar spheres. ${ }^{30,52}$

Work is currently underway to study the effect of various material properties inherent to different polymers on the ability of scaffolds to more effectively induce and control apatite deposition. For example, it is likely that polymer functional groups play a role in the nucleation and deposition of apatite. Our group tested the effect of the carboxylic acid group on apatite nucleation and growth on poly (methyl methacrylate) (PMMA) and poly (methyl methacrylate) - methacrylic acid (PMMA-MAA) scaffolds. Smaller apatite particles appeared in larger numbers after 30 days on PMMA versus PMMA-MMA, and the size of the particles increased while the frequency of the particles decreased with increased amounts of MMA. ${ }^{52}$ While this example showed that the presence of the functional groups led to fewer deposits, other functional groups such as $\mathrm{COOH}$ and $\mathrm{OH}$ led to increased nucleation rates. ${ }^{46}$ Other properties that may affect apatite nucleation and growth are polymer crystallinity, hydrophobicity/hydrophilicity of the surface, pore size, shape and interconnectivity. ${ }^{52}$ The optimal combination of scaffold parameters to induce nanoscale apatite deposition is yet to be discovered, and this is an area of ongoing research.

\section{BIOLOGICAL EFFECTS}

\section{The Biological Effects of Nanofibers}

Nanofibrous scaffolds enhance cellular functions compared to more traditional solid-walled (SW) scaffolds, enabling tissue engineers to fabricate more organized tissues and move closer to the functional replacement of ailing tissue. In this section, we will discuss the effects of nanofibrous materials on cellular attachment, proliferation, and differentiation, all of which are vital to functional tissue formation. It is important to note that the use of nanofibrous scaffolds in tissue engineering is in its early stages and there is limited data on the biological effects of nanofibers on cellular function and tissue formation.

\section{Attachment}

To proliferate, migrate and differentiate, most cells require anchorage. ${ }^{64}$ Therefore, cellular attachment is the first step toward the development of tissue. From an early stage in development, type I collagen provides the base attachment structure for cells within many tissues. ${ }^{65}$ As development progresses, other proteins and biomolecules are either adsorbed from the serum or secreted from the cells and join with type I collagen to form the various native ECM of differentiating tissues. The mature ECM then mediates cellular attachment, migration, proliferation and differentiation. The artificial ECMs used in tissue engineering attempt to mimic this native structure.

Several key attachment proteins (fibronectin, vitronectin and laminin) have been found to adsorb to the nanofibrous scaffolds at levels 2.6-3.9 times higher than SW scaffolds. ${ }^{66}$ Additionally, this adsorption was found to be selective and could not be explained by the surface area alone of the nanofibrous scaffold. ${ }^{66}$ This may provide cells attached to the nanofibrous scaffolds an ECM which more closely resembles in vivo conditions compared to SW scaffolds.

As a result, several studies have noted differences in the expression of integrins, a family of transmembrane receptors that govern cellular interactions with the ECM. ${ }^{67,68}$ Neonatal mouse osteoblasts cultured on nanofibrous scaffolds exhibited increased expression of integrins associated with collagen $(\alpha 2 \beta 1)$, fibronectin $(\alpha \mathrm{V} \beta 3)$ and vitronectin $(\alpha \mathrm{V} \beta 3)$ compared to SW scaffolds. Notably, the expression of $\alpha 2$ integrin remained up-regulated on the nanofibrous scaffolds compared to SW scaffolds even when collagen fibril formation was inhibited, ${ }^{68}$ potentially indicating a direct interaction between the cell and the nanofibrous scaffold via a $\alpha 2$ integrin-mediated dimer.

Changes in cellular morphology, more closely approximating that observed in vivo, have been observed on nanofibrous material compared to control. Neonatal mouse osteoblasts cultured on nanofibrous scaffolds exhibited long slender processes connecting to neighboring cells while cells on the SW scaffolds were flat and smooth (Figure 6) ${ }^{68}$ Similarly, processes were observed in human mesenchymal stem cells on nanofibrous thin films. ${ }^{69}$

The extracellular environment formed on nanofibers compared to that on SW surfaces has led to the report of increased cellular attachment with several cell lines including osteoblastic cells, ${ }^{66,68}$ fibroblasts, ${ }^{70}$ normal rat kidney cells, ${ }^{70}$ smooth muscle cells, ${ }^{71}$ neural stem cells ${ }^{72}$ and embryonic stem cells. ${ }^{73}$ This increased attachment across various cell types provides tissue engineers with a potential tool to generate functional tissues in shorter time frames than would be possible on more traditional scaffolds. 

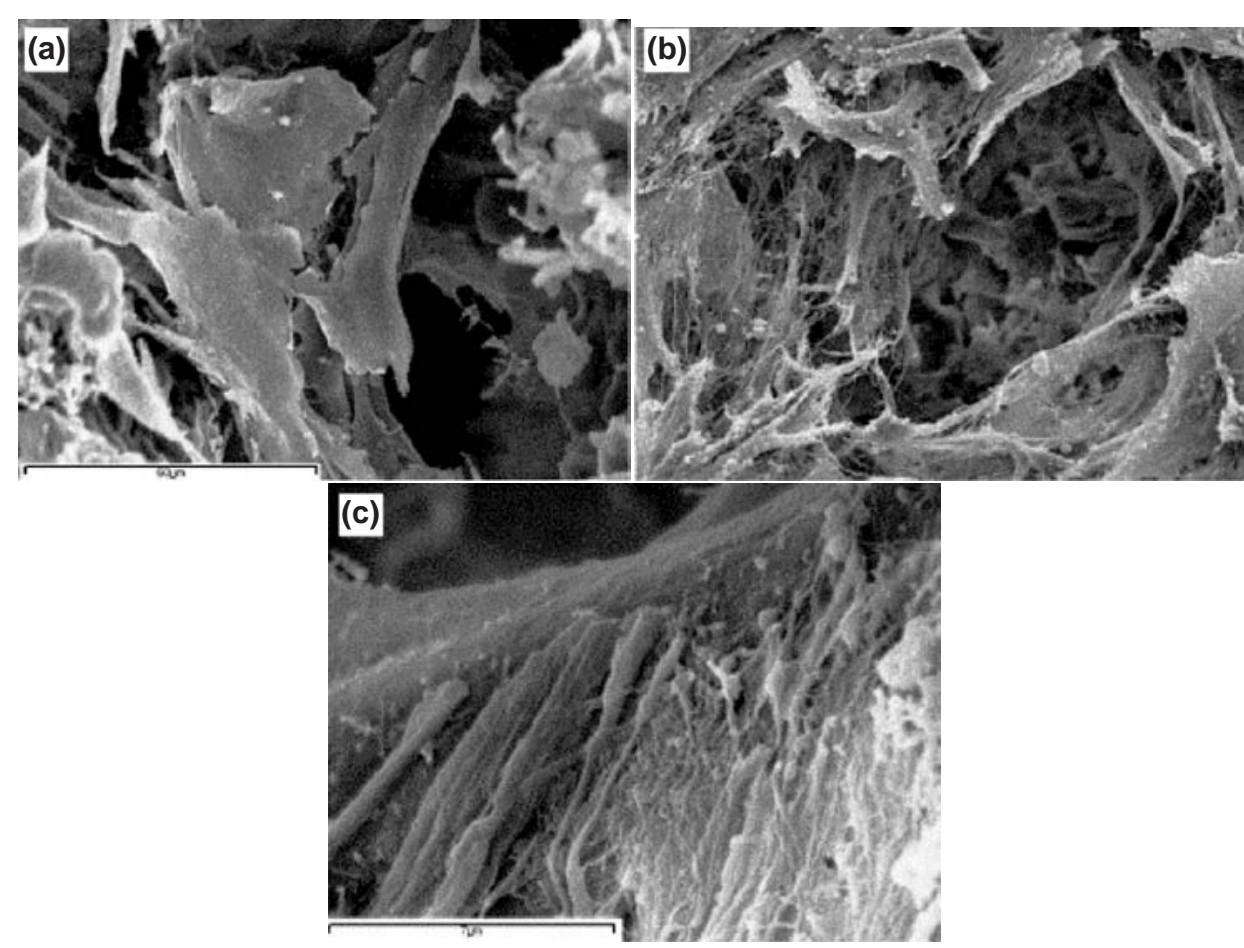

FI G URE 6 | Scanning electron microscopic views of neonatal mouse osteoblasts cultured for 3 days: (a) on the solid-walled (SW) scaffolds and (b, c) on the nanofibrous scaffolds. Original magnification; A and B $1000 \times$, C $8000 \times$. (Reprinted, with permission, from Ref. 68. Copyright 2004 Elsevier).

\section{Proliferation}

Most tissue engineering strategies require the migration and proliferation of cells to fully populate the scaffold to enable new tissue development. More rapid proliferation of the desired cell type in vivo would lead to a reduction in scar tissue formation.

Several cell types have been reported to exhibit increased proliferative ability on nanofibrous materials compared to controls. ${ }^{28,67,69-71,74}$ Specifically, pre-osteoblasts have shown a significant increase in proliferation from 7 to 12 days of culture on nanofibrous scaffolds compared to SW scaffolds, ${ }^{28}$ while chondrocytes have shown increased proliferation on nanofibers compared to control over 3 weeks of culture. ${ }^{67}$

\section{Differentiation}

The progression of cells from immature phenotypes to the highly specialized phenotypes present in tissues is a complex process governed by many factors. Nanofibers have enhanced the differentiation and function of several cell types including neural progenitors, ${ }^{25,75}$ hepatocytes, ${ }^{76,77}$ chondrocytes, ${ }^{78}$ and osteoblasts. ${ }^{28,68}$ Nanofibrous scaffolds have also been attributed with rescuing cells from regression to a more immature phenotype during expansion culture. ${ }^{67}$ However, this falls outside the scope of this review and will not be discussed here in detail. Bone is a tissue typically identified by its ECM. As immature cells differentiate toward the osteoblastic lineage, they begin to express a sequential series of markers which culminate in the secretion of proteins like osteocalcin and bone sialoprotein and the mineralization of the ECM. Alkaline phosphatase, an early marker of osteogenic differentiation, has been shown to be up-regulated on nanofibrous materials compared to controls in culture periods of 3 days or more in vitro ${ }^{68,79}$ while late osteogenic markers, such as osteocalcin and bone sialoprotein, have been shown to be up-regulated on nanofibers compared to control over culture periods of two or more weeks. $28,68,79$ Specifically, after 2 weeks of culture on nanofibrous scaffolds pre-ectoblastic cells expressed roughly 7.5 times more osteocalcin and 1.8 times more bone sialoprotein compared to SW scaffolds. ${ }^{28}$ The increased expression of these markers on nanofibrous scaffolds compared to SW scaffolds continued throughout the 6-week study.

Type I collagen is the only osteogenic marker down regulated on nanofibrous scaffolds compared to SW control scaffolds. ${ }^{28}$ However, several studies have found type I collagen distributed throughout the nanofibrous materials. ${ }^{16,80}$ The down-regulation of type I collagen could be because of accelerated maturation of the ECM on the nanofibrous material compared to control, or the ability of the cells to interact with the nanofibers in a manner similar to that of type I collagen therefore requiring less secreted type I collagen to complete the ECM. 
FIGURE 7 | In vitro response of nanofibrous (NF) and solid-walled (SW) poly(-lactic acid) (PLLA) scaffolds after seeding with MC3T3-E1 osteoblasts and cultured under differentiation conditions for 6 weeks. Shown are histological sections of representative areas within the scaffold. H\&E staining showing (a) overview of an NF scaffold, (b) overview of an SW scaffold, (c) center region of an NF scaffold, and (d) center region of an SW scaffold. Von Kossa's silver nitrate staining showing (e) center region of an NF scaffold, and ( $\mathrm{f}$ ) center region of an SW scaffold. Scale bars of (a), (b), (e), and (f); $500 \mu \mathrm{m}$. Scale bars of (c) and (d); $100 \mu \mathrm{m}$ * denotes the PLLA scaffold, \# a scaffold pore. Arrows in von Kossa stained sections denote mineralization. NF scaffolds retained a small amount of the histological dyes and therefore are more visible than the SW scaffolds in the pictures. (Reprinted, with permission, from Ref. 28. Copyright 2006 Elsevier).
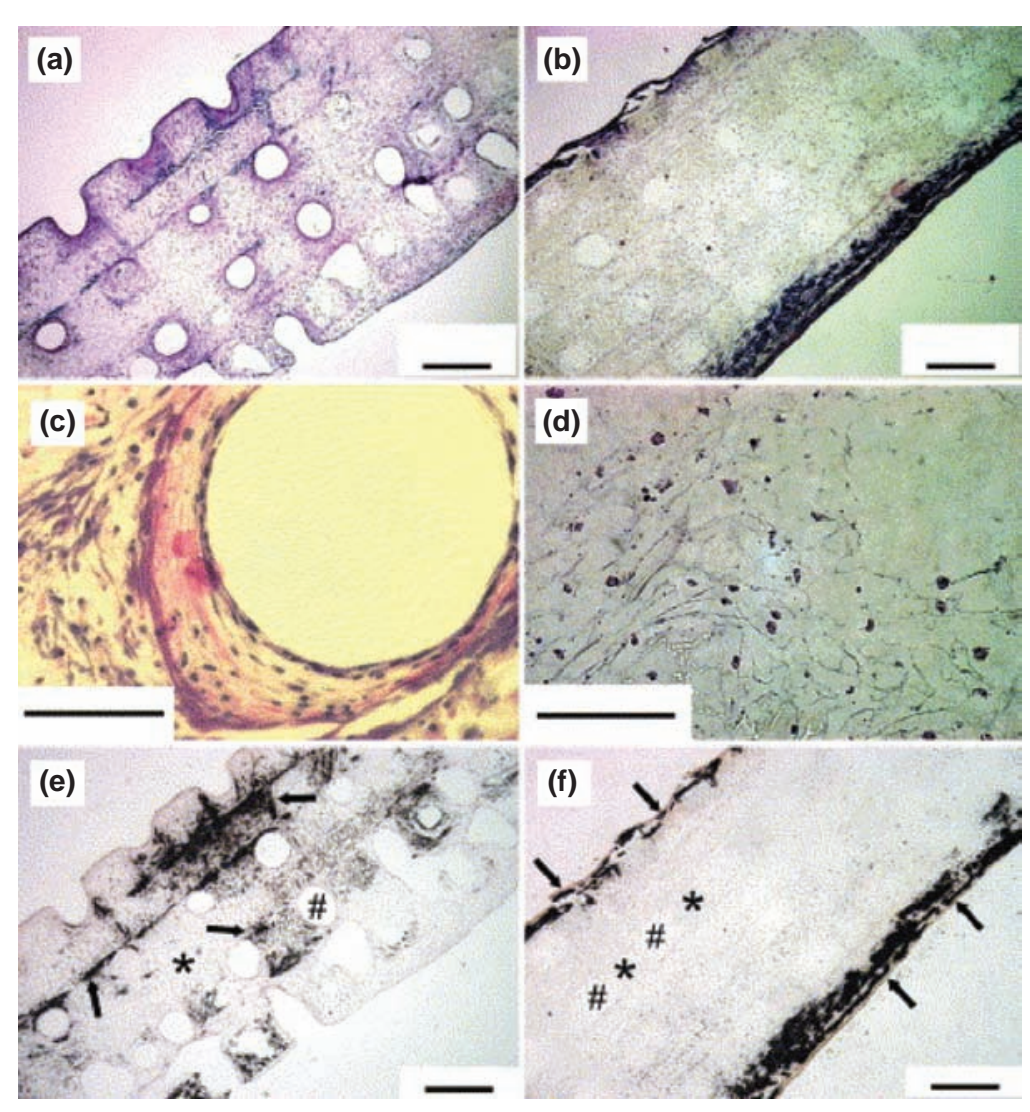

As cells begin to express markers of late stage bone differentiation, the ECM begins to mineralize. Several studies have reported increased mineralization of the nanofibrous scaffolds compared to control. ${ }^{28,68,81}$ One study found 13 times more physiologically deposited calcium on the nanofibrous scaffold than on the SW control scaffolds. ${ }^{68}$ The mineral on the nanofibrous scaffold was found to be more evenly distributed throughout the scaffolds than the mineral on the SW scaffolds, ${ }^{28}$ as seen in Figure 7.

Additionally, a more even cellular distribution and tissue-like cellular organization was seen on the nanofibrous scaffolds compared to SW control (Figure 7 ). With a combination of in vitro and in vivo culture, nanofibrous scaffolds have produced bone tissue containing vascularization, mineralization and embedded osteocyte-like cells. ${ }^{80}$ Overall, this indicates that nanofibrous scaffolds possess the potential to generate functional bone tissue. However, this will only be achieved with further enhancement of culture conditions and scaffold design.

\section{Biological Effects of Nanocomposite Scaffolds}

By decreasing the grain size of HA down to the nanoscale in dense substrates, osteoblast behavior is positively affected. Webster et al. showed an increase in osteoblast attachment, proliferation and differentiation on nanoscale HA (67 nm) versus microscale HA $(179 \mathrm{~nm}) .{ }^{82}$ While this phenomenon is not fully understood, it may be due in part to improved adsorption of key ECM proteins, including vitronectin and collagen, on the substrate. ${ }^{82}$ While the dense substrates used in the work of that group would not be useful tissue engineering scaffolds, this phenomenon of improved protein adsorption is observed in HA/PLLA composite scaffolds and is tied to a decrease in osteoblast apoptosis. ${ }^{83}$

\section{CONCLUSION}

Nanostructure in tissue engineering is of increasing importance. By mimicking the ECM and including nanoscale structural elements in tissue engineering scaffolds, cell response is affected at the cell-scaffold interface. Nanofibrous scaffolds are a synthetic replica of the naturally occurring ECM, which promote cell distribution and have the potential to promote new tissue formation. The addition of nanoscale apatite crystals to a polymer scaffold mimics the deposition of apatite crystals onto the ECM, as well as the multicomponent composite structure of bone. Integration 
of nanoparticles into scaffolds enhances biological regulation of cell behavior for regeneration. Further work is underway to study the effect of these components on mechanical properties, biological effects and the mechanisms by which these properties are changed.

This research was supported in kind by the NIH (DE015384, GM075849, DE017689,
P60DK020572-29S1: PXM), an NIH Stem Cell Core Pilot Grant (P20GM069985: PXM), an NIH Tissue Engineering and Training Grant (T32DE07057: LAS), an NIH Regenerative Science Training Grant (T90DK070071: IOS) and the NSF Graduate Research Fellowship Program (LAS).

\section{REFERENCES}

1. Wang S, Zinderman C, Wise R, Braun M. Infections and human tissue transplants: review of FDA MedWatch reports 2001-2004. Cell Tissue Bank 2007, 8:211-219.

2. Laurencin CT, Khan Y. Bone Graft Substitute Materials: eMedicine.com 2006, http://www. emedicine.com/orthoped/topic611.htm

3. Langer R, Vacanti JP. Tissue engineering. Science 1993, 260:920-926.

4. Chen VJ, Ma PX. Nano-fibrous poly(L-lactic acid) scaffolds with interconnected spherical macropores. Biomaterials 2004, 25(11):2065-2073.

5. Liu XH, Ma PX. Polymeric scaffolds for bone tissue engineering. Ann Biomed Eng 2004, 32(3):477-486.

6. Ma PX, Zhang RY. Synthetic nano-scale fibrous extracellular matrix. I Biomed Mater Res 1999, 46(1):60-72.

7. Zhang RY, Ma PX. Synthetic nano-fibrillar extracellular matrices with predesigned macroporous architectures. J Biomed Mater Res 2000, 52(2):430-438.

8. Fratzl P, Gupta HS, Paschalis EP, Roschger P. Structure and mechanical quality of the collagen-mineral nano-composite in bone. I Mater Chem 2004, $14: 2115-2123$.

9. Morton WJ. Method of Dispersing Fluids. US Patent 705691, 1902.

10. Reneker DH, Chun I. Nanometre diameter fibres of polymer, produced by electrospinning. Nanotechnology 1996, 7(3):216-223.

11. Li MY, Mondrinos MJ, Gandhi MR, Ko FK, Weiss AS, et al. Electrospun protein fibers as matrices for tissue engineering. Biomaterials 2005, 26(30):5999-6008.

12. Smith LA, Ma PX. Nano-fibrous scaffolds for tissue engineering. Colloids Surf B Biointerfaces 2004, 39(3):125-131.

13. Min BM, Lee G, Kim SH, Nam YS, Lee TS, et al. Electrospinning of silk fibroin nanofibers and its effect on the adhesion and spreading of normal human keratinocytes and fibroblasts in vitro. Biomaterials 2004, 25(7-8):1289-1297.

14. Jin HJ, Chen JS, Karageorgiou V, Altman GH, Kaplan DL. Human bone marrow stromal cell responses on electrospun silk fibroin mats. Biomaterials 2004, 25(6):1039-1047.

15. Luu YK, Kim K, Hsiao BS, Chu B, Hadjiargyrou M. Development of a nanostructured DNA delivery scaffold via electrospinning of PLGA and PLA-PEG block copolymers. J Control Release 2003, 89(2):341-353.

16. Yoshimoto H, Shin YM, Terai H, Vacanti JP. A biodegradable nanofiber scaffold by electrospinning and its potential for bone tissue engineering. Biomaterials 2003, 24(12):2077-2082.

17. Wnek GE, Carr ME, Simpson DG, Bowlin GL. Electrospinning of nanofiber fibrinogen structures. Nano Lett 2003, 3(2):213-216.

18. Kenawy ER, Layman JM, Watkins JR, Bowlin GL, Matthews JA, et al. Electrospinning of poly(ethyleneco-vinyl alcohol) fibers. Biomaterials 2003, 24(6):907-913.

19. Li WJ, Laurencin CT, Caterson EJ, Tuan RS, Ko FK. Electrospun nanofibrous structure: a novel scaffold for tissue engineering. J Biomed Mater Res 2002, 60(4):613-621.

20. Matthews JA, Wnek GE, Simpson DG, Bowlin GL. Electrospinning of collagen nanofibers. Biomacromolecules 2002, 3(2):232-238.

21. Deitzel JM, Kleinmeyer JD, Hirvonen JK, Tan NCB. Controlled deposition of electrospun poly(ethylene oxide) fibers. Polymer 2001, 42(19):8163-8170.

22. Srouji S, Kizhner T, Suss-Tobi E, Livne E, Zussman E. 3-D nanofibrous electrospun multilayered construct is an alternative ECM mimicking scaffold. I Mater Sci Mater Med 2008, 19:1249-1255.

23. Moroni L, Schotel R, Hamaan D, de Wijn JR, van Bitterswijk CA. 3D fiber-deposited electrospun integrated scaffolds enhance cartilage tissue formation. Adv Funct Mater 2008, 18:53-60.

24. Whitesides GM, Mathias JP, Seto CT. Molecular selfassembly and nanochemistry - a chemical strategy for the synthesis of nanostructures. Science 1991, 254(5036):1312-1319.

25. Silva GA, Czeisler C, Niece KL, Beniash E, Harrington DA, et al. Selective differentiation of neural progenitor cells by high-epitope density nanofibers. Science 2004, 303:1352-1355. 
26. Zhang SG. Fabrication of novel biomaterials through molecular self-assembly. Nat Biotechnol 2003, 21(10):1171-1178.

27. Hartgerink JD, Beniash E, Stupp SI. Self-assembly and mineralization of peptide-amphiphile nanofibers. Science 2001, 294(5547):1684-1688.

28. Chen VJ, Smith LA, Ma PX. Bone regeneration on computer-designed nano-fibrous scaffolds. Biomaterials 2006, 27:3973-3979.

29. Ma PX, Choi JW. Biodegradable polymer scaffolds with well-defined interconnected spherical pore network. Tissue Eng 2001, 7(1):23-33.

30. Wei GB, Ma PX. Macroporous and nanofibrous polymer scaffolds and polymer/bone-like apatite composite scaffolds generated by sugar spheres. J Biomed Mater Res A 2006, 78A(2):306-315.

31. Wei G, Ma PX. Macroporous and nanofibrous polymer scaffolds and polymer/bone-like apatite composite scaffolds generated by sugar spheres. J Biomed Mater Res 2006, 78A:306-315.

32. Liu XH, Smith LA, Wei G, Won YJ, Ma PX. Surface engineering of nano-fibrous poly(L-lactic acid) scaffolds via self-assembly technique for bone tissue engineering. J Biomed Nanotechnol 2005, 1(1):54-60.

33. Ratner BD, Bryant SJ. Biomaterials: Where we have been and Where we are going? Annu Rev Biomed Eng 2004, 6:41-75.

34. Shin H, Jo S, Mikos AG. Biomimetic materials for tissue engineering. Biomaterials 2003, 24(24):4353-4364.

35. Cui W, Li X, Zhou S, Weng J. In situ growth of hydroxyapatite within electrospun poly(DL-lactide) fibers. J Biomed Mater Res A 2007, 82(4):831-841.

36. Gao JM, Niklason L, Langer R. Surface hydrolysis of poly(glycolic acid) meshes increases the seeding density of vascular smooth muscle cells. J Biomed Mater Res 1998, 42(3):417-424.

37. Hu YH, Winn SR, Krajbich I, Hollinger JO. Porous polymer scaffolds surface-modified with arginineglycine-aspartic acid enhance bone cell attachment and differentiation in vitro. J Biomed Mater Res A 2003, 64A(3):583-590.

38. Nitschke M, Schmack G, Janke A, Simon F, Pleul D, et al. Low pressure plasma treatment of poly(3hydroxybutyrate): toward tailored polymer surfaces for tissue engineering scaffolds. J Biomed Mater Res 2002, 59(4):632-638.

39. Liu XH, Won YJ, Ma PX. Surface modification of interconnected porous scaffolds. J Biomed Mater Res A 2005, 74A(1):84-91.

40. Liu XH, Won YJ, Ma PX. Porogen-induced surface modification of nano-fibrous poly(L-lactic acid) scaffolds for tissue engineering. Biomaterials 2006, 27(21):3980-3987.
41. Wei G, Jin Q, Giannobile WV, Ma PX. The enhancement of osteogenesis by nano-fibrous scaffolds incorporating rhBMP-7 nanospheres. Biomaterials 2007, 28:2087-2096.

42. Hulbert SF, Young FA, Mathews RS, Klawitter JJ, Talbert CD, et al. Potential of ceramic materials as permanantly implantable skeletal protheses. J Biomed Mater Res 1970, 4:433-456.

43. Hench LL. Bioceramics: From concept to clinic. J Am Ceram Soc 1991, 74(7):1487-1510.

44. Jarcho M. Calcium phosphate ceramics as hard tissue prosthetics. Clin Orthop Rel Res 1981, 157:259-278.

45. Zhang R, Ma PX. Poly( $\alpha$-hydroxyl acids)/hydroxyap atite porous composites for bone-tissue engineering. I. Preparation and morphology. J Biomed Mater Res 1999, 44:446-455.

46. Zhang R, Ma PX. Porous poly( $\iota$-lactic acid)/apatite composites created by biomimetic process. J Biomed Mater Res 1999, 45:285-293.

47. Ma PX, Zhang R, Xiao G, Franceschi R. Engineering new bone tissue in vitro on highly porous $\operatorname{poly}(\alpha-$ hydroxyl acids)/hydroxyapatite composite scaffolds. $J$ Biomed Mater Res 2001, 54:284-293.

48. Woo KM, Chen VJ, Ma PX. Nano-fibrous scaffolding architecture selectively enhances protein adsorption contributing to cell attachment. J Biomed Mater Res A 2003, 67A(2):531-537.

49. Liao SS, Cui FZ, Zhang W, Feng QL. Hierarchically biomimetic bone scaffold materials: NanoHA/collagen/PLA composite. J Biomed Mater Res B Appl Biomater 2004, 69B:158-165.

50. Wei G, Ma PX. Structure and properties of nanohydoxyapatite/polymer composite scaffolds for bone tissue engineering. Biomaterials 2004, 25:4749-4657.

51. Kim SS, Park MS, Gwak SJ, Choi CY, Kim BS. Accelerated bonelike apatite growth on porous polymer/ceramic composite scaffolds in vitro. Tissue Eng 2006, 12(10):2997-3006.

52. Zhang R, Ma PX. Biomimetic polymer/apatite composite scaffolds for mineralized tissue engineering. Macromol Biosci 2004, 4:100-111.

53. Wang H, Li Y, Zuo Y, Li J, Ma S, et al. Biocompatibility and osteogenesis of biomimetic nano-hydroxyapatite/polyamide composite scaffolds for bone tissue engineering. Biomaterials 2007, 28(22):3338-3348.

54. Kim HW. Biomedical nanocomposites of hydroxyapatite/polycaprolactone obtained by surfactant mediation. J Biomed Mater Res 2007, 83(1):169-177.

55. Zhang Y, Tanner KE. Effect of filler surface morphology on the impact behaviour of hydroxyapatite reinforced high density polyethylene composites. J Mater Sci Mater Med 2008, 19(2):761-766. 
56. Kim H-W, Kim H-E, Salih V. Stimulation of osteoblast responses to biomimetic nanocomposites of gelatinhydroxyapatite for tissue engineering scaffolds. Biomaterials 2005, 26:5221-5230.

57. Li Z, Yubao L, Aiping Y, Xuelin P, Xuejiang W, et al. Preparation and in vitro investigation of chitosan/nanohydroxyapatite composite used as bone substitute materials. J Mater Sci Mater Med 2005, 16(3):213-219.

58. Du C, Cui FZ, Feng QL, Zhu XD, deGroot K. Tissue response to nano-hydroxyapatite/collagen composite implants in marrow cavity. J Biomed Mater Res 1998, 42:540-548.

59. Du C, Cui FZ, Zhu XD, deGroot K. Three-dimensional nano-HAp/collagen matrix loading with osteogenic cells in organ culture. J Biomed Mater Res 1999, 44:407-415.

60. Smith IO, McCabe LR, Baumann MJ. MC3T3-E1 osteoblast attachment and proliferation on porous hydroxyapatite scaffolds fabricated with nanophases powder. Int J Nanomed 2006, 1:189-194.

61. Yoneda S, Guthrie WF, Khatri SBD, Wang CA, FW. In vitro Biocompatibility of Hydrolytically Degraded Poly (d, l-lactic acid). 7th World Biomaterials Congress, Sydney, 2004, 1324.

62. Boskey AL. Biomineralization: Conflicts, challenges, and opportunities. J Cell Biochem Suppl 1998, 30/31:83-91.

63. Boskey AL. Biomineralization: an overview. Connect Tissue Res 2003, 44:5-9.

64. Alberts B, Johnson A, Lewis J, Raff M, Roberts K, et al. Molecular Biology of the Cell. New York: Graland Science; 2002.

65. Kadler K. Matrix loading: assembly of extracellular matrix collagen fibrils during embryogenesis. Birth Defects Res C Embryo Today 2004, 72:1-11.

66. Woo KM, Chen VJ, Ma PX. Nano-fibrous scaffolding architecture selectively enhances protein adsorption contributing to cell attachment. J Biomed Mater Res A 2003, 67(2):531-537.

67. Li WJ, Danielson KG, Alexander PG, Tuan RS. Biological response of chondrocytes cultured in threedimensional nanofibrous poly(E-caprolactone) scaffolds. J Biomed Mater Res 2003, 67A:1105-1114.

68. Woo KM, Jun JH, Chen VJ, Seo J, Baek JH, et al. Nano-fibrous scaffolding promotes osteoblast differentiation and biomeneralization. Biomaterials 2007, 28:335-343.

69. Shih YV, Chen CN, Tsai SW, Wang YJ, Lee OK. Growth of mesenchymal stem ells on electrospun Type I collagen nanofibers. Stem Cells 2006, 24:2391-2397.

70. Schindler M, Ahmed I, Kamal J, Nur-E-Kamal A, Grafe TH, et al. A synthetic nanofibrillar matrix promotes in vivo-like organization and morphogenesis for cells in culture. Biomaterials 2005, 26:5624-5631.
71. Xu CY, Inai R, Kotaki M, Ramakrishna S. Aligned biodegradable nanofibrous structure: a potential scaffold for blood vessel engineering. Biomaterials 2004, 25:877-886.

72. Yang F, Xu CY, Kotaki M, Wang S, Ramakrishna S. Characterization of neural stem cells on electrospun poly(L-lactic acid) nanofibrous scaffolds. I Biomater Sci Polymer Edn 2004, 15(12):1483-1497.

73. Nur-E-Kamal A, Ahmed I, Kamal J, Schindler M, Meiners S. Three-demensional nanofibrillar surfaces promote self-renewal in mouse embryonic stem cells. Stem Cells 2006, 24:426-433.

74. Lee CH, Shin HO, Cho IH, Kang YM, Kim IA, et al. Nanofiber alignment and direction of mechanical strain affect the ECM productions of humand ACL fibroblast. Biomaterials 2005, 26:1261-1270.

75. Yang F, Xu C, Kotaki M, Wang S, Ramakrishna S. Characterization of Neural stem cells on electrospun poly(L-lactic acid) nanofibrous scaffolds. J Biomater Sci Polymer Edn 2004, 15(12):1483-1497.

76. Chua KN, Lim WS, Zhang P, LU H, Wen J, et al. Stable immobilization of rat hepatocyte spheroids on galactosylated nanofibers. Biomaterials 2005, 26:2537-2547.

77. Semino CE, Merok JR, Crane GG, Panagiotakos G, Zhang S. Functional differentiation of hepatocyte-like spheroid structures from putative liver progenitor cells in three-deminional peptide scaffolds. Differentiation 2003, 71:262-270.

78. Li W, Danielson K, Alexander P, Tuan R. Biological response of chondrocytes cultured in three-dimensional nanofibrous poly(E-caprolactone) scaffolds. J Biomed Mater Res 2003, 67A:1105-1114.

79. Li W, Tuli R, Huang X, Laquerriere P, Tuan R. Multilineage differentiation of human mesnchymal stem cells in a three-dimensional nanofibrous scaffold. Biomaterials 2005, 26:5158-5166.

80. Shin M, Yoshimoto H, Vacanti JP. In Vivo bone tissue engineering using mesenchymal stem cells on a novel electrospun nanofibrous scaffold. Tissue Eng 2004, 10(1/2):33-41.

81. Hosseinkhani H, Hosseinkhani M, Tian F, Kobayashi $\mathrm{H}$, Tabata $\mathrm{Y}$. Bone regeneration on a collagen sponge self-assembled peptide-amphiphile nanofiber hybrid scaffold. Tissue Eng 2007, 13:11-19.

82. Webster TJ, Ergun C, Doremus RH, Siegel RW, Bizios R. Enhanced functions of osteoblasts on nanophase ceramics. Biomaterials 2000, 21:1803-1810.

83. Woo KM, Seo J, Zhang R, Ma PX. Suppression of apoptosis by enhanced protein adsorption on polymer/hydroxyapatite composite scaffolds. Biomaterials 2007, 28:2622-2630. 